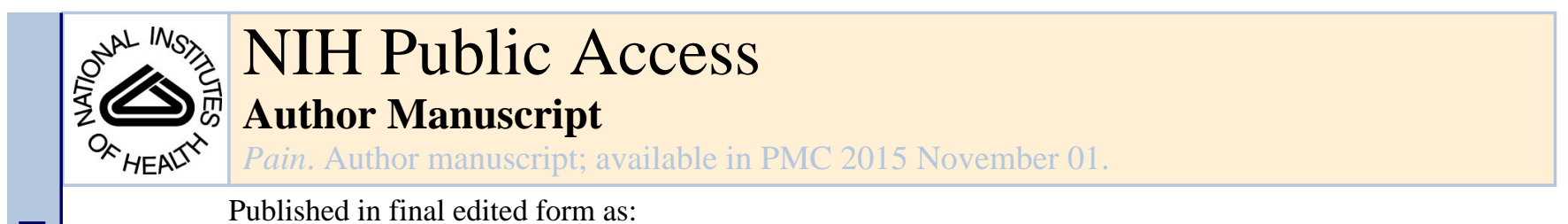

Published in final edited form as:

Pain. 2014 November ; 155(11): 2390-2399. doi:10.1016/j.pain.2014.09.009.

\title{
Epistasis Between Polymorphisms in COMT, ESR1, and GCH1 Influences COMT Enzyme Activity and Pain
}

\author{
Shad B. Smith ${ }^{1}$, Ilkka Reenilä2 ${ }^{2}$ Pekka T. Männistö ${ }^{2}$, Gary D. Slade ${ }^{1}$, William Maixner ${ }^{1}$, Luda \\ Diatchenko ${ }^{1,3}$, and Andrea G. Nackley ${ }^{1, *}$ \\ ${ }^{1}$ Center for Pain Research and Innovation, School of Dentistry, University of North Carolina, \\ Chapel Hill, NC, 27599 USA 2Division of Pharmacology and Toxicology, Faculty of Pharmacy, \\ University of Helsinki, Helsinki, FIN-00014 Finland ${ }^{3}$ Alan Edwards Pain Centre For Research on \\ Pain, McGill University, Montreal, Canada H3A 0C7
}

\begin{abstract}
Abnormalities in the enzymatic activity of catechol- $O$-methyltransferase (COMT) contribute to chronic pain conditions, such as temporomandibular disorders (TMD). Thus, we sought to determine the effects of polymorphisms in COMT and functionally-related pain genes in the COMT pathway (estrogen receptor 1: ESRl, guanosine-5-triphosphate cyclohydrolase 1: GCH1, methylenetetrahydrofolate reductase: $M T H F R$ ) on COMT enzymatic activity, musculoskeletal pain, and pain-related intermediate phenotypes among TMD cases and healthy controls. Results demonstrate that the COMT rs4680 ( val $^{158}$ met) polymorphism is most strongly associated with outcome measures, such that individuals with the minor A allele (met) exhibit reduced COMT activity, increased TMD risk, and increased musculoskeletal pain. Epistatic interactions were observed between the COMT rs4680 polymorphism and polymorphisms in GCHI and ESRI. Among individuals with the COMT met allele, those with two copies of the GCH1 rs10483639 minor $\mathrm{G}$ allele exhibit normalized COMT activity and increased mechanical pain thresholds. Among individuals with the COMT val allele, those with two copies of the ESR1 rs3020377 minor A allele exhibit reduced COMT activity, increased bodily pain, and poorer self-reported health. These data reveal that the $\mathrm{GCH} 1$ minor $\mathrm{G}$ allele confers a protective advantage among met carriers, while the ESRI minor A allele is disadvantageous among val carriers. Furthermore, these data suggest that the ability to predict the downstream effects of genetic variation on COMT activity is critically important to understanding the molecular basis of chronic pain conditions.
\end{abstract}

(C) 2014 Elsevier B.V. on behalf of International Association for the Study of Pain. All rights reserved.

Corresponding Author: Andrea G. Nackley, Center for Pain Research and Innovation, School of Dentistry, CB 7450, University of North Carolina, Chapel Hill, NC 27599-7450, Phone: (919) 537-3204, Fax: (919) 966-5339, andrea_nackley@ dentistry.unc.edu.

Publisher's Disclaimer: This is a PDF file of an unedited manuscript that has been accepted for publication. As a service to our customers we are providing this early version of the manuscript. The manuscript will undergo copyediting, typesetting, and review of the resulting proof before it is published in its final citable form. Please note that during the production process errors may be discovered which could affect the content, and all legal disclaimers that apply to the journal pertain. 


\section{Keywords}

catecholamines; gene-gene interaction; gene expression; temporomandibular disorders (TMD); fibromyalgia

\section{Introduction}

Catechol-O-methyltransferase (COMT) is a ubiquitously expressed enzyme that regulates the bioavailability of catecholamines, playing a key role in maintaining basic physiologic functions such as sympathetic tone, mood, and inflammation, that influence pain. Through alternative promoters and translation initiation sites, the COMT gene yields two distinct proteins: soluble COMT (S-COMT) and membrane-bound COMT (MB-COMT) [42,62]. The COMT gene locus is rich with single nucleotide polymorphisms (SNPs), several of which have been associated with chronic pain and pain-related phenotypes.

Most COMT genetic association studies have focused on the common rs4680 SNP. The rs4680 A allele has been associated with increased susceptibility to post-surgical pain [1,24,32], fibromyalgia [3,15,29,44], and arthritis [65]. Additionally, rs 4680 has been associated with clinically relevant intermediate phenotypes such as experimental pain [72], anxiety [23], depression, and attention [67]. The A allele produces a nonsynonymous change from valine to methionine at codon 158 ( $\mathrm{val}^{158} \mathrm{met}$ ), resulting in a less thermostable enzyme with reduced activity [41]. Studies have consistently shown that the met allele codes for a $25-40 \%$ reduction in enzyme activity measured in human red blood cells $[53,59,69]$ and tissues [7] as well as in lysates from transfected cells $[41,46,56]$. Thus, the val ${ }^{158}$ met allele represents a major source of individual variation in COMT activity.

More recently, investigators have identified additional polymorphisms in the COMT gene locus that, while not independently associated with pain, interact with the $\mathrm{val}^{158} \mathrm{met}$ allele. Haplotypes consisting of one SNP in the S-COMT promoter (rs6269 G/A) and two SNPs in the coding region ( $r 4633 \mathrm{C} / \mathrm{T}$ and $\mathrm{rs} 4818 \mathrm{C} / \mathrm{G}$ ) together with rs $4680 \mathrm{G} / \mathrm{A}$ have been associated with clinical and experimental pain. Specifically, the ATCA and ACCG haplotypes have been associated with susceptibility to post-surgical pain [26], fibromyalgia [66], and temporomandibular disorders (TMD) [19] as well as experimental pain sensitivity [19] and treatment response [60]. In vitro studies have shown that the ACCG haplotype codes for an $80 \%$ reduction in enzymatic activity due to formation of a stable mRNA secondary structure that is more resistant to translation [46]. Thus, SNPs in distinct COMT gene loci can act alone or in concert to influence enzyme activity and pain.

Emerging evidence suggests that the size and direction of COMT polymorphic effects can be modified by epistatic interactions with genes in convergent molecular pathways. For example, the effects of the met allele on disease risk have been shown to be augmented by a low activity variant of the methylenetetrahydrofolate reductase (MTHFR) gene, which regulates the bioavailability of S-adenosyl-L-homocysteine (SAH; a strong, noncompetitive inhibitor of COMT) [45]. Thus, we hypothesize that polymorphisms in MTHFR and functionally-related genes implicated in pain, including estrogen receptor 1 (ESRI; which regulates COMT gene expression [35,70]) and guanosine-5-triphosphate cyclohydrolase 1 
( $G C H 1$; a rate-limiting enzyme for a cofactor for catecholamine synthesis [47]), interact with polymorphisms in $C O M T$ to influence COMT enzymatic activity and pain.

In order to test this hypothesis, the present study characterized the relationship between SNPs located in genes of the COMT pathway (COMT, MTHFR, ESRI, and GCH1), COMT enzymatic activity, musculoskeletal pain, and related intermediate phenotypes.

\section{Materials and Methods}

\section{Subjects}

Subjects were 398 white females aged 18-60 years enrolled in a case-control study of TMD. These subjects were recruited between 2005-2009 in Chapel Hill, NC, using advertisements placed in local newspapers and flyers posted in and around the UNC Health Center, including tertiary care clinics that provide treatment for people with chronic orofacial pain. All subjects signed written informed consent for experimental protocols and for genotyping and biomarker analysis, and gave a blood sample. A detailed overview of recruitment protocols including case definition and exclusion criteria has been described previously [57]. Briefly, cases ( $n=200)$ had to report facial pain for at least five days during the previous two weeks and be diagnosed with TMD arthralgia or myalgia following the Research Diagnostic Criteria (RDC) for TMD [21]. Digital palpation of muscle and joint cranial sites was performed using a force of $0.45 \mathrm{~kg}$. Controls $(\mathrm{n}=198)$ had no self-reported history of orofacial pain within the preceding six months and no diagnosis for TMD either prior to or during the study examination. Enrolment was limited to females due to the higher prevalence of TMD in women than men [10], and to whites to avoid problems of population stratification in assessing genetic associations.

\section{Assessment of Bodily Pain and Experimental Pain}

At the time of the clinical examination, all study subjects were evaluated for the presence of bodily pain. Three pounds of digital palpation pressure were applied bilaterally for 2 seconds to each of the following predefined locations modeled after ACR's 1990 criteria for fibromyalgia tender points examination [71]: occiput, trapezius, supraspinatus, lower cervical, second rib, lateral epicondyle, knee, gluteal, and greater trochanter. At each location, a response of pain to palpation was recorded.

Following the clinical examination, study subjects completed a battery of quantitative sensory testing (QST) assessments. First, thermal pain was assessed by applying a thermode to the forearm that increased in temperature at a rate of $0.5^{\circ} \mathrm{C} / \mathrm{sec}$. Thermal pain threshold was defined as the temperature at which pain was first reported, while tolerance was defined as the highest temperature that could be tolerated (with an upper limit of $50^{\circ} \mathrm{C}$ ). Second, central sensitization was assessed using repeated thermal stimuli of $50^{\circ} \mathrm{C}$ applied to the right hand.[49] Pain was rated on a 0-100 numerical rating scale (NRS) after each of 10 pulses, of $0.5 \mathrm{sec}$ duration repeated once every three seconds. Plots of each subject's pattern of response at each temperature were used to derive two summary measures of temporal "windup" (highest NRS response minus lowest NRS response and slope of a linear regression line fitted for the first five NRS responses) and two summary measures of 
thermal sensitivity (first NRS and sum of all NRS responses). Third, pressure pain thresholds in response to a hand-held pressure algometer [34] were assessed bilaterally at two extracranial sites: trapezius muscles and the lateral epicondyle. Pressure threshold at each site was recorded as the algometer loading $(\mathrm{kg})$ at which pain was first detected. Descriptive characteristics of bodily pain and experimental pain phenotypes measured in TMD cases and controls enrolled in this study have been published previously $[11,12,57]$.

\section{Assessment of Self-reported Pain, Health, and Psychological Mood}

Subjects completed several questionnaires to assess the severity of their pain and painrelated traits. Pain intensity and unpleasantness was measured by the Gracely Pain Scale, which asks subjects to report their lowest, average, and maximal pain on a scale of 0 to 100 [28]. Self-ratings of physical and mental health were measured by the Short Form 12 version 2 (SF-12v2), which asks questions in six domains: global health rating, physical functioning, physical roles, emotional functioning, emotional roles, and pain interference. Published scoring algorithms [68] were used to compute scores for each domain, ranging from 0 to 100 , with higher values signifying better function and health. Stress was measured by the Perceived Stress Scale (PSS), which contains 10 questions about frequency of daily stressors on a five-point scale ranging from "never" to "very often" [16]. Responses were summed for an overall score. Additional domains of stress were measured by the Symptoms Checklist90 Revised (SCL-90-R), which consists of 90 items that describe a feeling or thought, scored on a 5 point scale ranging from "not at all distressed" to "extremely distressed" [17]. It provides ratings of psychological distress in nine symptom areas: somatization, obsessivecompulsive, interpersonal sensitivity, depression, anxiety, hostility, phobic anxiety, paranoid ideation, and psychoticism. Psychological mood was measured by the Profile of Mood States- Bi-Polar (POMS), which consists of 72 questions used to compute six subscales of mood-related states (e.g., elated-depressed and energetic-tired) [39]. Descriptive characteristics of self-reported pain, health, and psychological mood phenotypes measured in TMD cases and controls enrolled in this study have been published previously $[11,12,57]$.

\section{Genotyping}

DNA extracted from whole blood donated by study subjects was genotyped by BeckmanCoulter Genomics (Morrisville, NC) using the Algynomics Pain Research Panel v.1.0 (http://algynomics.com/pain-research-panel.html). This platform is a dedicated array for the targeted assessment of genes involved in acute and chronic pain conditions, utilizing the Affymetrix MegAllele platform. The panel genotypes 3295 SNPs in 358 candidate genes whose protein products are linked to biological pathways that influence pain transmission, inflammatory response, or psychological state. Genotyping calls were checked for quality using utilities implemented in PLINK version 1.07. [50] All 398 samples exhibited Caucasian ancestry and an overall genotype call rate $<95 \%$. All SNPs used for this study exhibited a call rate $>95 \%$, minor allele frequency $>1 \%$ in either case or control groups, and agreement across repeated samples $>98 \%$. The potential for population stratification to influence association statistics was assessed by calculating the lambda statistic [18]; no evidence was found for inflation of test statistics $(\lambda<1.0)$. 
This analysis was limited to four genes directly or indirectly involved in regulating COMT activity: COMT, ESRI, GCH1, and MTHFR. Within the COMT gene locus, 9 SNPs passed quality filters (Supplemental Table 1: table of COMT activity associations). The rs4633 SNP also passed quality filters but was in very strong $\left(\mathrm{r}^{2}=1.0\right) \mathrm{LD}$ with $\mathrm{rs} 4680$ and so was not included in further analysis. Within the ESRI, GCH1, and MTHFR loci, 27, 10, and 7 SNPs, respectively, passed quality filters. For the complete list of ESRI, GCH1, and MTHFR SNPs, please refer to Supplemental Table 4.

\section{COMT Activity Assay}

S-COMT activity was measured in red blood cells (RBCs) following the method of Schultz et al. [55] with some modifications [64]. RBCs were hemolyzed in four volumes of $1 \mathrm{mM}$ sodium phosphate buffer (instead of water), enzyme incubation was performed in $\mathrm{pH} 7.4$ (instead of 7.8) for $60 \mathrm{~min}$, using $500 \mu \mathrm{M}$ of 3,4-dihydroxy benzoic acid (DHBAc; instead of $400 \mu \mathrm{M}$ ) as a substrate, and the samples were filtered with $0.45 \mu \mathrm{M}$ pore size membranes using syringe before HPLC. In principle, vanillic acid generated from the DHBAc substrate was quantified with a HPLC system. It consisted of a sample autoinjector (Shimadzu, Prominence SIL-20AC, Kyoto, Japan), a pump (Jasco pu- 2080, Tokyo, Japan), an RP-18 column ( $3 \mu \mathrm{m}, 4.6 \times 100 \mathrm{~mm}$; Waters Spherisorb, Milford, MA, USA) with precolumn, column heater (Croco-Cil, Bordeaux, France), a coulometric detector (ESA model Coulochem III detector and a model 5011A cell; ESA Inc., Chelmsford, MA, USA; E1 detector potential was $-0 \mathrm{~V}$ and that of $\mathrm{E} 2$ analytical detector $+0.5 \mathrm{~V}$ ) and Azur 5.0 software (Datalys, France). The mobile phase consisted of 0.1 M Na2HPO4 (pH 3.3), $0.15 \mathrm{mM}$ EDTA and $25 \%$ methanol; the flow-rate was $1.0 \mathrm{ml} / \mathrm{min}$. The protein levels of the samples were analyzed using the Bradford assay [8]. COMT activity was expressed as pmol of vanillic acid formed per $\mathrm{mg}$ of protein in one minute.

This RBC-COMT assay has been validated with human samples containing either normal or low COMT levels. Intra-assay coefficient of variation (CV\%) was typically $<5 \%$ and in inter-assay $<15 \%$. Assay was highly linear for vanillic acid $(r=0.9996-0.9998)$ and precision $\mathrm{CV} \%$ for vanillic acid was $0.3 \%$ at $2 \mu \mathrm{M}$ and $4.8 \%$ at $0.2 \mu \mathrm{M}$.

\section{Statistical Analysis}

Genetic association analyses were performed using PLINK and JMP, Version 7 (SAS Institute Inc., Cary, NC) software packages. Haplotype phasing was performed in PLINK, using COMT SNPs rs6269 and rs4633 to construct haplotypes Low Pain Sensitivity (LPS), Average Pain Sensitivity (APS), and High Pain Sensitivity (HPS), as described previously. [19] The phasing algorithm succeeded in phasing all haplotypes and diplotypes with no ambiguity. Association tests were conducted by logistic (for binary case-status variables) or linear (for quantitative variables) regression, to test the null hypothesis that outcome measures were equal between genotype groups. Regression models included age as a covariate for variables that were associated with age in a univariate analysis.

Primary analyses were conducted to explore the relationship between COMT, ESR1, GCH1, and MTHFR genotype with COMT activity and case status. We first assessed the effects of all genotyped COMT polymorphisms and haplotypes of COMT on erythrocyte COMT 
activity, using a codominant model. For subsequent analyses of COMT genetic effects and epistasis, we used the SNP rs4680 ( $\mathrm{al}^{158} \mathrm{met}$ ), which results in high activity (valine) and low activity (methionine) variants of COMT. To follow the usual convention regarding variant effect direction, statistical analyses on this SNP considered the val allele as the referent and the met allele as the variant, although in this sample the met allele was actually more frequent. We also analyzed SNPs in three COMT pathway genes, MTHFR, ESR1, and $G C H 1$, using univariate tests of association. For these SNPs, we screened codominant genetic models and compared our results with previous reports in the literature showing evidence for alternate models of inheritance. We then constructed 2-way interaction models between rs4680 and SNPs within MTHFR, ESRI, and GCH1 to identify SNPs in these genes that modulate the effects of $\mathrm{val}^{158}$ met on COMT activity and TMD risk, and selected the SNP in each gene with the strongest evidence for interaction. For clarity of presentation, we modeled interaction effects by testing genotype differences in pathway gene SNPs within carriers of either val (for ESRl) or met (for GCHI).

Secondary analyses were also conducted to explore the relationship between COMT pathway genotypes and intermediate phenotypes relevant to TMD. We tested the effects of SNPs in COMT, ESRI, GCH1, and MTHFR on intermediate variables of pain sensitivity and psychological distress. Finally, exploratory analyses were conducted to test for epistatic effects of val $^{158}$ met and selected SNPs in ESRI and GCHI on COMT activity and TMD risk. We constructed a 3-way interaction model that contained three main effect terms for val $^{158}$ met, rs3020377 (dominant), and GCH1 (recessive); three 2-way interaction terms for each pairwise combination of the three loci; and one 3-way interaction term.

For analyses of genetic association, we set the threshold for significance at an uncorrected pvalue of $p<0.05$. Although this does not account for the number of tests performed, the purpose of the study was to characterize the interactive effects of multiple genes on an array of nociceptive and affective phenotypes in order to detect consistent patterns among genotype groups. The analyses were designed to reproduce previous significant findings and extend them by investigating more complex epistatic interactions in a broad set of outcome measures. However, given the increased risk of false positives, novel results should be considered exploratory until confirmed in independent cohorts.

\section{Results}

Primary analyses were focused on exploring the relationship between COMT, ESR1, GCH1, and MTHFR genotype with COMT activity and case status. Secondary analyses were focused on exploring the relationship between these COMT pathway genotypes and intermediate phenotypes (e.g., pain and mood) relevant to TMD.

\section{Effect of COMT genotype on COMT activity}

COMT activity level was strongly associated $(\mathrm{p}<0.001)$ with almost all of the COMT SNPs, including rs4680 $\mathrm{val}^{158} \mathrm{met}$, (Supplementary Table 1) as shown previously

$[7,41,46,53,56,59,69]$. Each additional copy of the $m e t$ allele resulted in a $0.31 \mathrm{pmol} / \mathrm{min} / \mathrm{mg}$ protein decrease in measured COMT activity (Fig. 1A). Haplotype analysis likewise showed that the subjects homozygous for the APS haplotype (which contains met at rs4680) had the 
lowest COMT activity, while subjects with two copies of LPS or HPS (which contain val at rs4680) had the highest activity (Supplementary Fig. 1).

The independent effects of the individual SNPs are confounded by linkage disequilibrium with val $^{158}$ met, the SNP with the largest effect on COMT activity (Fig. 1B), so each SNP was tested in a regression model that included terms for a main effect of rs4680 and an interaction between rs4680 and the respective SNP. After adjustment for val ${ }^{158}$ met, most of the SNPs failed to show an independent effect on COMT (Fig. 1C and Supplementary Table 1), although the direction of effect of several SNPs that appeared to increase COMT activity showed a smaller effect in the opposite direction. For the representative SNP rs737865, the presence of one or two copies of the minor $\mathrm{G}$ allele decreased COMT activity across all genotypes of $\mathrm{val}^{158}$ met (Fig. 1D), with an overall effect of $-0.07 \mathrm{pmol} / \mathrm{min} / \mathrm{mg}$ protein per copy of the $\mathrm{G}$ allele $(\mathrm{p}<0.001)$. No COMT SNPs showed a significant interaction with val $^{158}$ met.

\section{Effect of val ${ }^{158}$ met on pain phenotypes}

In addition to COMT activity, we tested association between rs 4680 and the primary outcome measure of TMD case status (Supplementary Table 2). The SNP was associated with TMD after adjustment for age, with the $v a l$ allele being protective $(\mathrm{OR}=0.72, \mathrm{p}=$ 0.032). We also examined the effects of this SNP on a battery of QST and psychosocial profile measures, as a secondary descriptive analysis. Of these intermediate variables, only tests of sensitivity to mechanical pressure were significantly associated, including pressure point thresholds taken at temporalis (age-adjusted beta $=-0.13, \mathrm{p}=0.027$ ), masseter (ageadjusted beta $=-0.14, \mathrm{p}=0.026$ ), TMJ (beta $=-0.13, \mathrm{p}=0.037$ ) and lateral epicondyle (beta $=-0.24, \mathrm{p}=0.007$ ) sites.

\section{Effect of ESR1, GCH1, and MTHFR genotype on COMT activity}

Three genes contained in the genotyping panel in addition to COMT were selected for analysis due to their known involvement in COMT regulation and pain: ESR1, GCH1, and MTHFR. We examined 43 SNPs from these genes for genotype effects on COMT enzymatic activity (Supplementary Table 3). Three SNPs from the ESRI gene were associated with COMT activity, including rs3020377 (beta $=-0.05, \mathrm{p}=0.04$ ), rs726281 (beta $=-0.06, \mathrm{p}=$ 0.02 ) and rs3020407 (beta $=-0.06, \mathrm{p}=0.02$ ) (Fig. 2). These SNPs are correlated due to moderate LD between them (Supplementary Fig. 2), and likely represent a single effect.

\section{2-way interactions on COMT activity: COMT × ESR1/GCH1/MTHFR}

The val $^{158}$ met polymorphism exerts the greatest regulatory effect on COMT enzymatic activity, but the magnitude of this effect may be modified by other genes in convergent pathways. In order to identify variants that modulate the effect of val $^{158}$ met on COMT activity, 2-way interaction models were constructed between this SNP and the SNPs in the selected COMT pathway genes (Supplementary Table 3). In MTHFR, two SNPs showed interaction ( $\mathrm{p}<0.01$ ): rs 2274976 , an $\arg ^{594}$ gln non-synonymous change, and rs2066470, a pro ${ }^{39}$ pro synonymous variant. There was no significant interaction with rs 1801133 $(\mathrm{p}=0.48)$, which has been previously shown to interact with $\mathrm{val}^{158}$ met to influence schizophrenia risk [45]. Two SNPs in ESR1 exceeded the p<0.05 threshold for the 
interaction, including rs6912184 $(\mathrm{p}=0.049)$ and $\mathrm{rs} 1884052(\mathrm{p}=0.035)$. The SNPs associated with COMT activity in the previous main effect analysis did not show interaction with val $^{158}$ met. However, further analysis of the SNP rs3020377 using a dominant model showed that carriers of the minor $\mathrm{G}$ allele had significantly lower levels of COMT activity in val carriers ( $\mathrm{p}=0.0021$ ), but no difference in met carriers. In GCH1, rs 10483639 was the most strongly associated $(\mathrm{p}=0.003)$ in a locus of three neighboring SNPs (including rs752688, rs4411417, rs8007201) in the same haploblock (Supplementary Fig. 1b).

We selected one SNP from each of the three genes to carry forward to analysis of pain and pain-related intermediate phenotypes. In this selection step, in deciding between SNPs showing strong association test p-values, we prioritized SNPs with existing evidence for biological relevance to COMT activity and nociceptive pathways. For MTHFR, none of the associated SNPs were previously shown to interact with COMT; rs2066470 was chosen because it was the SNP with the highest MAF among those with strong interaction test pvalues, in order to maximize power to see effects in subjects carrying the minor allele. The ESRI SNP rs3020377 was selected due to a strong effect on COMT activity in the highactivity val group alone, as well as a previous report that this SNP interacts with val ${ }^{158}$ met to influence endocrine-dependent mood disorders [33]. For GCH1, rs10483639 was selected as it showed a strong interaction with $\mathrm{val}^{158} \mathrm{met}$, and because it is a marker of a risk haplotype identified previously [43]. This haplotype was reported to have a recessive inheritance, so for consistency with these findings we used this model for subsequent association tests with rs10483639.

\section{Effect of ESR1 genotype on COMT activity and pain phenotypes among COMT (val) carriers}

The significant difference between ESR1 rs3020377 genotypes within val carriers suggests that variation in the estrogen receptor gene modulates COMT enzymatic activity in subjects with a genetic predisposition toward high activity due to the rs4680 val allele, but does not affect COMT activity in subjects with overall low activity (Fig. 3A). We investigated this interaction model in the panel of pain-related phenotypes. We observed similar interactions, with effects in carriers of the val allele, in several clinical measures of pain. Relative to val carriers with no copies of the rs 3020377 minor $\mathrm{G}$ allele, subjects with 1 or 2 copies of the $\mathrm{G}$ allele reported higher scores on the SF12 physical functioning subscale ( $p=0.017$, Fig. 3B), as well as higher pain intensity ( $p=0.018$, Fig. $3 \mathrm{C}$ ) and a trend toward higher pain unpleasantness ratings $(p=0.07$, Fig 3D) using the Gracely Scale. The number of body sites with pain upon palpation was also higher in val carriers with 1 or 2 copies of the $\mathrm{G}$ allele, although this trend was nonsignificant ( $\mathrm{p}=0.08$, Fig. 3E).

\section{Effect of GCH1 genotype on COMT activity and pain phenotypes among COMT (met) carriers}

In contrast with the ESRI modulatory effect observed in val carriers, modulatory effects of the GCH1 SNP were observed within carriers of the rs 4680 met allele. Subjects with 0 or 1 copy of the minor $\mathrm{C}$ allele of rs 10483639 had significantly lower levels of COMT activity ( $\mathrm{p}$ $=0.0030$ ) than homozygous carriers of the $\mathrm{C}$ allele (Fig. 4A). These subjects also had a reduced threshold for algometer pressure pain across all tested sites, although only the 
association with the temporalis site was significant $(\mathrm{p}=0.031$, Fig. 4B). However, subjects that were homozygous for $\mathrm{C}$ were more likely to score negatively on measures of mood and affect, including the depression ( $p=0.025$, Fig. 4C) and hostility $(p=0.017$, Fig. 4D) subscales of the SCL90, the elated-depressed ( $p=0.016$, Fig. 4E) and energetic $(p=0.025$, Fig. 4F) axes of the POMS, and the distress domain on the PSS ( $p=0.038$, Fig. 4G). These subjects also reported a decreased ability to function in daily life due to emotional problems on the SF12 ( $\mathrm{p}=0.049$, Fig. $4 \mathrm{H})$.

\section{Effect of MTHFR genotype on COMT activity and pain phenotypes among COMT (val/met) carriers}

Interaction tests were also performed between the MTHFR SNP rs2066470 and val ${ }^{158}$ met as with the ESRI and GCHI SNPs, with strong effects observed in met carriers between rs2066470 genotypes on multiple clinical, affective, and molecular phenotypes. However, despite selecting this SNP due to its relatively greater MAF within the gene locus, there were still not enough subjects to make statistical comparisons between genotype groups (data not shown).

\section{Three gene interaction on COMT activity and TMD risk}

Finally, we constructed 3-way genetic interaction models to evaluate the main effects and interactions of COMT val ${ }^{158}$ met, ESRl rs3020377 (using a dominant model), and GCH1 rs10483639 (recessive) on COMT enzymatic activity and TMD risk. We did not include MTHFR in further tests of epistasis due to low frequency of the minor allele of the selected SNP. Significant effects were observed on COMT activity (Fig. 5A) for the main effects of the COMT ( $\mathrm{p}<0.001)$ and ESRI ( $\mathrm{p}=0.013) \mathrm{SNPs}$, and the interaction term for COMT $\times$ $G C H 1(\mathrm{p}=0.029)$; a trend for an association for COMT $\times E S R 1$ approached significance $(\mathrm{p}$ $=0.058)$. The 3 -way interaction term was not significant $(\mathrm{p}=0.75)$. For the TMD variable (Fig. 5B), a pattern was observed of coinciding higher COMT activity and lower TMD risk due to variation in $\mathrm{GCH} 1$, in the met carriers only. In val carriers, there was an apparent relationship between $E S R I$ and $G C H 1$ on COMT activity, such that the $G C H 1$ major allele increased COMT activity in ESR1 major allele homozygotes only, although the GCH1 minor allele coincided with decreased TMD frequency in both ESR1 groups. However, none of the main effect or interaction terms were significantly associated with TMD, so these preliminary findings require further investigation in larger cohorts to confirm.

\section{Discussion}

COMT plays a critical role in the development and maintenance of pain. Understanding how variability at the genetic level maps onto variability at the functional level of this enzyme, will provide insight into the molecular mechanisms that drive maladaptive pain conditions, such as TMD. Here, we identify SNPs in COMT and ESRI that are independently associated with COMT enzymatic activity. Consistent with our hypothesis, we also identify interactions between SNPs in COMT and those in functionally-related genes that influence COMT enzymatic activity and pain. 


\section{Polymorphisms in COMT and ESR1 Genes are Independently Associated with COMT Enzymatic Activity}

Our results demonstrate that the major source of individual variation in COMT activity is driven by the $\mathrm{val}^{158}$ met allele. The number of met alleles was dose-dependently associated with COMT activity, such that individuals with one allele exhibited a $27 \%$ reduction and those with two alleles exhibited a 55\% reduction. These results are consistent with those from other studies, demonstrating that the met allele codes for a more thermolabile COMT enzyme $[7,41,46,53,56,59,69]$.

Of the remaining 8 COMT SNPs genotyped, only the rs $737865 \mathrm{~A} / \mathrm{G}$ allele independently accounted for additional variation in COMT activity. After adjusting for the effects of vall met, a modest association between rs737865 and COMT activity was revealed, such that individuals with two copies of the $\mathrm{G}$ allele exhibited a $18.4 \%$ reduction. The rs737865 SNP is positioned in intron 1 of $M B-C O M T$ and, while direct evidence for potential functional effects of rs 737865 is lacking, the $\mathrm{G}$ allele has been associated with decreased COMT expression in human brain [9]. Additionally, a clinical study of pain following motor vehicle collision demonstrated that a haplotype containing the rs $737865 \mathrm{G}$ allele was predictive of higher pain interference.

Common COMT haplotypes were also tested for association with COMT activity. While previous studies by our group showed that cells expressing the ACCG COMT haplotype (constructed from rs6269, rs4633, rs4618, and rs4680) exhibited an $80 \%$ reduction in COMT activity, here we found no link between COMT haplotype and circulating COMT activity. This discrepancy between in vitro and in vivo effects of ACCG haplotype on COMT activity is likely due to methodological differences in the two studies. The initial in vitro studies established a clear link between ACCG and COMT activity in isolated cell lines overexpressing the construct [46]. However, subsequent in vitro studies found that the extent by which the ACCG haplotype down-regulated COMT expression was cell linedependent [63]. COMT activity as determined in the present in vivo study reflects cumulative regulation by a chorus of genetic variants expressed in red blood cells.

Finally, we evaluated SNPs in genes whose products regulate the expression or activity of COMT. Of the 43 SNPs in MTHFR, ESRI, and GCH1, we identified 3 SNPs in intron 4 of ESRl that were associated with COMT enzymatic activity. These included the rs 3020377 $\mathrm{A} / \mathrm{G}$ allele, the rs $726281 \mathrm{~A} / \mathrm{G}$ allele, and the rs $3020407 \mathrm{~A} / \mathrm{G}$ allele. Individuals with one or two copies of the rs3020377 minor $\mathrm{G}$ allele exhibited an $8 \%$ reduction in COMT activity. Individuals with the rs 726281 or rs3020407 minor $\mathrm{G}$ allele exhibited a dose-dependent decrease in COMT activity, such that those with one copy had an $8 \%$ reduction and those with two copies had a $12 \%$ reduction. As all three ESRI SNPs are in close proximity and moderate LD, their effects are unlikely to be independent. ESR1 can bind to estrogen response elements (EREs) in the promoter region of COMT to downregulate its transcription $[35,70]$. Thus, we speculate that rs3020377 G, rs726281 G, rs3020407 G, or another SNP in high linkage with those tested codes for increased levels of ESR1, resulting in the subsequent downregulation of COMT. 


\section{Polymorphisms in Genes of the COMT Pathway Interact to Influence COMT Enzymatic Activity, Musculoskeletal Pain, and Mood}

While several distinct alleles in COMT and ESRI were independently associated with COMT activity, the interaction analyses were focused on $v a l^{158}$ met because it accounted for the greatest degree of individual variation. Our results demonstrate that the net size and direction of val/met effects are modified by epistatic interactions with SNPs in convergent molecular pathways. We identified a significant interaction between the COMT val ${ }^{158}$ met allele and the ESR1 rs3020377 A/G allele. Among individuals with the COMT val allele, those with two copies of the ESRI minor G allele exhibited reduced COMT activity, increased bodily pain, and poorer self-reported health. While this is the first study to demonstrate an interaction between COMT val and ESR1 rs3020377 with respect to COMT activity and pain, our findings are in line with a previous report showing that rs3020377 interacts with $\mathrm{val} / \mathrm{val}$ (but not $\mathrm{val} / \mathrm{met}$ or $\mathrm{met} / \mathrm{met}$ ) to influence risk of premenstrual dysphoric disorder [33].

We also identified a significant interaction between the COMT $v a l^{158}$ met allele and the rs 10483639 G/C allele, located in the 3'UTR of GCH1. GCH1 is the rate limiting enzyme for the synthesis of tetrahydrobiopterin (BH4), which is a cofactor necessary for the synthesis of catecholamines and nitric oxide- molecules critical for pain [14,22,52,54]. Among individuals with the COMT met allele, those with two copies of the GCH1 minor C allele exhibited normalized COMT activity and increased mechanical pain thresholds. The pain-protective effects of the $\mathrm{C}$ allele are in line with previous findings that a haplotype containing rs $10483639 \mathrm{C}$ is associated with reduced pain following back surgery and reduced analgesic requirements following oral surgery [38,40,61]. The GCH1 haplotype produces functional biologic effects, coding for reduced $\mathrm{GCH} 1$ gene expression and reduced BH4 bioavailability [2]. Reduced BH4, in turn, reduces levels of catecholamines and NO to alleviate pain.

In agreement with previous studies [45], we identified a statistical 2-way interaction between MTHFR SNPs and val $^{158}$ met on COMT activity. However, there were too few subjects carrying the rs 2274976 or rs2066470 minor alleles to characterize their effects stratified by rs4680 genotype. Although the present cohort was underpowered to investigate the interaction on TMD risk and other intermediate phenotypes, it would be valuable to explore this finding in a larger study.

Finally, we developed a three gene model that takes into account the sum of COMT val ${ }^{158}$ met, GCH1 rs10483639 G/C, and ESR1 rs3020377 A/G allelic effects on COMT activity and TMD risk. This model illustrates 1) the protective role of $G C H 1$ rs $10483639 \mathrm{C}$ on COMT activity and TMD risk among met carriers, 2) the deleterious role of ESRI rs3020377 G on COMT activity and TMD risk among val carriers with only 0 or 1 copy of the $G C H 1$ rs10483639 C allele, and 3) the correlation between COMT activity patterns and TMD risk, such that individuals with lower COMT activity are at greater risk for TMD.

It is important to note that the influence of COMT, GCH1, and ESRI polymorphisms on COMT enzymatic activity is likely modified by environmental events that produce physical and emotional stress, inflammation, and/or injury [27,30,51]. An example of gene- 
environment interaction was illustrated by Slade and colleagues, who found that among individuals with ATCA or ACCG COMT haplotypes, TMD incidence was $23 \%$ for those with a history of orthodontic treatment and $0 \%$ for those with no history of orthodontic treatment [58]. In addition, the influence of genetic polymorphism on COMT activity is likely modified by sex. It is well-established that males and females differ with respect to COMT activity levels, with males exhibiting higher levels in brain [13] and peripheral tissues [7], as well as COMT-dependent nociception [5] and behavioral traits [31]. Further, a growing number of studies demonstrate sex-dependent differences in the role of ESRI SNPs $[6,25,37]$ and COMT val/met $[4,20,36,48]$ in disease susceptibility. As the present study enrolled only females, we were unable to explore interactions between sex, genotype, and COMT activity. Thus, future studies should also account for the effects of sex and nongenetic factors on COMT activity and related phenotypes.

\section{Conclusion}

In conclusion, polymorphisms located in distinct gene loci can act alone or in concert to influence the expression and activity of corresponding pain-relevant molecules such as COMT. The COMT val ${ }^{158}$ met allele accounts for the greatest amount of individual variation in COMT activity, yet its effects are modified by SNPs in functionally-related ESRI and $G C H 1$ genes. Among individuals with the COMT val allele, those with two copies of the ESR1 rs3020377 minor G allele exhibit reduced COMT activity, increased bodily pain, and poorer self-reported health. Among individuals with the COMT met allele, those with two copies of the GCH1 rs10483639 minor C allele exhibit normalized COMT activity and increased mechanical pain thresholds. Thus, the ESR1 minor $\mathrm{G}$ allele is deleterious among val carriers, while the $\mathrm{GCH} 1$ minor $\mathrm{C}$ allele confers a protective advantage among met carriers. This finding is further confirmed in the three gene model, which also illustrates the parallels between low COMT activity and increased TMD risk. Ultimately, measuring functional levels of COMT will provide information representing the sum of molecular regulatory events affected by genetic polymorphisms as well as environmental events.

\section{Supplementary Material}

Refer to Web version on PubMed Central for supplementary material.

\section{Acknowledgments}

The authors wish to thank Ms. Liisa Lappalainen, M.Sci. for the COMT activity assays.

This work was supported by the National Institutes of Health, including the National Institute of Neurological Disorders and Stroke [grant number R01 NS072205 to A.G.N.] and the Eunice Kennedy Shriver National Institute of Child Health and Human Development [grant number K12 HD052191 to A.G.N.], National Institute of Neurological Disorders and Stroke [grant number P01 NS045685 to A.G.N. and W.M.], and National Institute of Dental and Craniofacial Research [grant numbers U01 DE017018 to L.D. and W.M., and K12 DE022793 to S.B.S].

W. M. and L. D. are owners of Algynomics, Inc. (Chapel Hill, NC). S.B.S., G.D.S., and A.G.N. have received consulting fees and/or stock options in Algynomics. 


\section{References}

1. Ahlers SJ, Elens LL, van Gulik L, van Schaik RH, van Dongen EP, Bruins P, Tibboel D, Knibbe CA. The Val158Met polymorphism of the COMT gene is associated with increased pain sensitivity in morphine-treated patients undergoing a painful procedure after cardiac surgery. Br J Clin Pharmacol. 2013; 75(6):1506-1515. [PubMed: 23210659]

2. Antoniades C, Shirodaria C, Van Assche T, Cunnington C, Tegeder I, Lotsch J, Guzik TJ, Leeson P, Diesch J, Tousoulis D, Stefanadis C, Costigan M, Woolf CJ, Alp NJ, Channon KM. GCH1 haplotype determines vascular and plasma biopterin availability in coronary artery disease effects on vascular superoxide production and endothelial function. J Am Coll Cardiol. 2008; 52(2):158165. [PubMed: 18598896]

3. Barbosa FR, Matsuda JB, Mazucato M, de Castro Franca S, Zingaretti SM, da Silva LM, MartinezRossi NM, Junior MF, Marins M, Fachin AL. Influence of catechol-O-methyltransferase (COMT) gene polymorphisms in pain sensibility of Brazilian fibromialgia patients. Rheumatol Int. 2012; 32(2):427-430. [PubMed: 21120493]

4. Barnett JH, Heron J, Ring SM, Golding J, Goldman D, Xu K, Jones PB. Gender-specific effects of the catechol-O-methyltransferase Val108/158Met polymorphism on cognitive function in children. Am J Psychiatry. 2007; 164(1):142-149. [PubMed: 17202556]

5. Belfer I, Schreiber KL, Shaffer JR, Shnol H, Blaney K, Morando A, Englert D, Greco C, Brufsky A, Ahrendt G, Kehlet H, Edwards RR, Bovbjerg DH. Persistent postmastectomy pain in breast cancer survivors: analysis of clinical, demographic, and psychosocial factors. J Pain. 2013; 14(10):11851195. [PubMed: 23890847]

6. Boada M, Antunez C, Lopez-Arrieta J, Caruz A, Moreno-Rey C, Ramirez-Lorca R, Moron FJ, Hernandez I, Mauleon A, Rosende-Roca M, Martinez-Lage P, Marin J, Tarraga L, Alegret M, Pedrajas JR, Urda N, Royo JL, Saez ME, Gayan J, Gonzalez-Perez A, Real LM, Ruiz A, Galan JJ. Estrogen receptor alpha gene variants are associated with Alzheimer's disease. Neurobiol Aging. 2012; 33(1):198, e115-e124. [PubMed: 20674091]

7. Boudikova B, Szumlanski C, Maidak B, Weinshilboum R. Human liver catechol-Omethyltransferase pharmacogenetics. Clin Pharmacol Ther. 1990; 48(4):381-389. [PubMed: 2225698]

8. Bradford MM. A rapid and sensitive method for the quantitation of microgram quantities of protein utilizing the principle of protein-dye binding. Anal Biochem. 1976; 72:248-254. [PubMed: 942051]

9. Bray NJ, Buckland PR, Williams NM, Williams HJ, Norton N, Owen MJ, O'Donovan MC. A haplotype implicated in schizophrenia susceptibility is associated with reduced COMT expression in human brain. Am J Hum Genet. 2003; 73(1):152-161. [PubMed: 12802784]

10. Carlsson, GE.; Le Resche, L. Temporomandibular Disorders and Related Pain Conditions. Sessle, BJ.; Bryant, PS.; Dionne, RA., editors. Vol. 4. Seattle: IASP Press; 1995. p. 211-226.

11. Chen H, Nackley A, Miller V, Diatchenko L, Maixner W. Multisystem dysregulation in painful temporomandibular disorders. J Pain. 2013; 14(9):983-996. [PubMed: 23721875]

12. Chen H, Slade G, Lim PF, Miller V, Maixner W, Diatchenko L. Relationship between temporomandibular disorders, widespread palpation tenderness, and multiple pain conditions: a case-control study. J Pain. 2012; 13(10):1016-1027. [PubMed: 23031401]

13. Chen LX, Fang Q, Chen Q, Guo J, Wang ZZ, Chen Y, Wang R. Study in vitro and in vivo of nociceptin/orphanin FQ(1-13)NH2 analogues substituting N-Me-Gly for Gly2 or Gly3. Peptides. 2004; 25(8):1349-1354. [PubMed: 15350703]

14. Chen X, Levine JD. Epinephrine-induced excitation and sensitization of rat C-fiber nociceptors. J Pain. 2005; 6(7):439-446. [PubMed: 15993822]

15. Cohen H, Neumann L, Glazer Y, Ebstein RP, Buskila D. The relationship between a common catechol-O-methyltransferase (COMT) polymorphism val(158) met and fibromyalgia. Clin Exp Rheumatol. 2009; 27 Suppl 56(5):S51-S56. [PubMed: 20074440]

16. Cohen S, Kamarck T, Mermelstein R. A global measure of perceived stress. J Health Soc Behav. 1983; 24(4):385-396. [PubMed: 6668417]

17. Derogatis LR, Lipman RS, Covi L. SCL-90: an outpatient psychiatric rating scale--preliminary report. Psychopharmacol Bull. 1973; 9(1):13-28. [PubMed: 4682398] 
18. Devlin B, Roeder K. Genomic control for association studies. Biometrics. 1999; 55(4):997-1004. [PubMed: 11315092]

19. Diatchenko L, Slade GD, Nackley AG, Bhalang K, Sigurdsson A, Belfer I, Goldman D, Xu K, Shabalina SA, Shagin D, Max MB, Makarov SS, Maixner W. Genetic basis for individual variations in pain perception and the development of a chronic pain condition. Hum Mol Genet. 2005; 14(1):135-143. [PubMed: 15537663]

20. Domschke K, Deckert J, O'Donovan MC, Glatt SJ. Meta-analysis of COMT val158met in panic disorder: ethnic heterogeneity and gender specificity. Am J Med Genet B Neuropsychiatr Genet. 2007; 144B(5):667-673. [PubMed: 17357147]

21. Dworkin SF, LeResche L. Research diagnostic criteria for temporomandibular disorders: review, criteria, examinations and specifications, critique. J Craniomandib Disord. 1992; 6(4):301-355. [PubMed: 1298767]

22. Fan W, Huang F, Wu Z, Zhu X, Li D, He H. The role of nitric oxide in orofacial pain. Nitric Oxide. 2012; 26(1):32-37. [PubMed: 22138296]

23. Fernandez-de-Las-Penas C, Ambite-Quesada S, Gil-Crujera A, Cigaran-Mendez M, PenacobaPuente C. Catechol-O-methyltransferase Val158Met polymorphism influences anxiety, depression, and disability, but not pressure pain sensitivity, in women with fibromyalgia syndrome. J Pain. 2012; 13(11):1068-1074. [PubMed: 23025981]

24. Fernandez-de-las-Penas C, Fernandez-Lao C, Cantarero-Villanueva I, Ambite-Quesada S, RivasMartinez I, del Moral-Avila R, Arroyo-Morales M. Catechol-O-methyltransferase genotype (Val158met) modulates cancer-related fatigue and pain sensitivity in breast cancer survivors. Breast Cancer Res Treat. 2012; 133(2):405-412. [PubMed: 21898113]

25. Gasparotto AS, Sprinz E, Lazzaretti RK, Kuhmmer R, Silveira JM, Basso RP, Pinheiro CA, Silveira MF, Ribeiro JP, Mattevi VS. Genetic polymorphisms in estrogen receptors and sexual dimorphism in fat redistribution in HIV-infected patients on HAART. AIDS. 2012; 26(1):19-26. [PubMed: 22011627]

26. George SZ, Wallace MR, Wright TW, Moser MW, Greenfield WH 3rd, Sack BK, Herbstman DM, Fillingim RB. Evidence for a biopsychosocial influence on shoulder pain: pain catastrophizing and catechol-O-methyltransferase (COMT) diplotype predict clinical pain ratings. Pain. 2008; 136(12):53-61. [PubMed: 17686583]

27. Goldstein DS. Catecholamines and stress. Endocr Regul. 2003; 37(2):69-80. [PubMed: 12932192]

28. Gracely RH. Evaluation of multi-dimensional pain scales. Pain. 1992; 48(3):297-300. [PubMed: 1594252]

29. Gursoy S, Erdal E, Herken H, Madenci E, Alasehirli B, Erdal N. Significance of catechol-Omethyltransferase gene polymorphism in fibromyalgia syndrome. Rheumatol Int. 2003; 23(3): 104-107. [PubMed: 12739038]

30. Harden RN, Rudin NJ, Bruehl S, Kee W, Parikh DK, Kooch J, Duc T, Gracely RH. Increased systemic catecholamines in complex regional pain syndrome and relationship to psychological factors: a pilot study. Anesth Analg. 2004; 99(5):1478-1485. table of contents. [PubMed: 15502052]

31. Harrison PJ, Tunbridge EM. Catechol-O-methyltransferase (COMT): a gene contributing to sex differences in brain function, and to sexual dimorphism in the predisposition to psychiatric disorders. Neuropsychopharmacology. 2008; 33(13):3037-3045. [PubMed: 17805313]

32. Hickey OT, Nugent NF, Burke SM, Hafeez P, Mudrakouski AL, Shorten GD. Persistent pain after mastectomy with reconstruction. J Clin Anesth. 2011; 23(6):482-488. [PubMed: 21911195]

33. Huo L, Straub RE, Roca C, Schmidt PJ, Shi K, Vakkalanka R, Weinberger DR, Rubinow DR. Risk for premenstrual dysphoric disorder is associated with genetic variation in ESR1, the estrogen receptor alpha gene. Biol Psychiatry. 2007; 62(8):925-933. [PubMed: 17599809]

34. Jaeger B, Reeves JL. Quantification of changes in myofascial trigger point sensitivity with the pressure algometer following passive stretch. Pain. 1986; 27(2):203-210. [PubMed: 3797015]

35. Jiang H, Xie T, Ramsden DB, Ho SL. Human catechol-O-methyltransferase down-regulation by estradiol. Neuropharmacology. 2003; 45(7):1011-1018. [PubMed: 14573393] 
36. Karayiorgou M, Altemus M, Galke BL, Goldman D, Murphy DL, Ott J, Gogos JA. Genotype determining low catechol-O-methyltransferase activity as a risk factor for obsessive-compulsive disorder. Proc Natl Acad Sci U S A. 1997; 94(9):4572-4575. [PubMed: 9114031]

37. Kelly TN, Rebholz CM, Gu D, Hixson JE, Rice TK, Cao J, Chen J, Li J, Lu F, Ma J, Mu J, Whelton PK, He J. Analysis of sex hormone genes reveals gender differences in the genetic etiology of blood pressure salt sensitivity: the GenSalt study. Am J Hypertens. 2013; 26(2):191200. [PubMed: 23382403]

38. Lee PJ, Delaney P, Keogh J, Sleeman D, Shorten GD. Catecholamine-o-methyltransferase polymorphisms are associated with postoperative pain intensity. Clin J Pain. 2011; 27(2):93-101. [PubMed: 20842020]

39. Lorr, M.; Mcnair, DM. Profie of Mood States-Bipolar form (POMS-BI). San Diego, CA: Educational and Industrial Testing Service; 1988.

40. Lotsch J, Belfer I, Kirchhof A, Mishra BK, Max MB, Doehring A, Costigan M, Woolf CJ, Geisslinger G, Tegeder I. Reliable screening for a pain-protective haplotype in the GTP cyclohydrolase 1 gene $(\mathrm{GCH} 1)$ through the use of 3 or fewer single nucleotide polymorphisms. Clin Chem. 2007; 53(6):1010-1015. [PubMed: 17363416]

41. Lotta T, Vidgren J, Tilgmann C, Ulmanen I, Melen K, Julkunen I, Taskinen J. Kinetics of human soluble and membrane-bound catechol O-methyltransferase: a revised mechanism and description of the thermolabile variant of the enzyme. Biochemistry. 1995; 34(13):4202-4210. [PubMed: 7703232]

42. Lundstrom K, Salminen M, Jalanko A, Savolainen R, Ulmanen I. Cloning and characterization of human placental catechol-O-methyltransferase cDNA. DNA Cell Biol. 1991; 10(3):181-189. [PubMed: 1707278]

43. Lupo PJ, Chapa C, Nousome D, Duhon C, Canfield MA, Shaw GM, Finnell RH, Zhu H. A GCH1 haplotype and risk of neural tube defects in the National Birth Defects Prevention Study. Mol Genet Metab. 2012; 107(3):592-595. [PubMed: 23059057]

44. Matsuda JB, Barbosa FR, Morel LJ, Franca Sde C, Zingaretti SM, da Silva LM, Pereira AM, Marins M, Fachin AL. Serotonin receptor (5-HT 2A) and catechol-O-methyltransferase (COMT) gene polymorphisms: triggers of fibromyalgia? Rev Bras Reumatol. 2010; 50(2):141-149. [PubMed: 21125150]

45. Muntjewerff JW, Gellekink H, den Heijer M, Hoogendoorn ML, Kahn RS, Sinke RJ, Blom HJ. Polymorphisms in catechol-O-methyltransferase and methylenetetrahydrofolate reductase in relation to the risk of schizophrenia. Eur Neuropsychopharmacol. 2008; 18(2):99-106. [PubMed: 17716874]

46. Nackley AG, Shabalina SA, Tchivileva IE, Satterfield K, Korchynskyi O, Makarov SS, Maixner W, Diatchenko L. Human catechol-O-methyltransferase haplotypes modulate protein expression by altering mRNA secondary structure. Science. 2006; 314(5807):1930-1933. [PubMed: 17185601]

47. Nagatsu T, Ichinose H. Regulation of pteridine-requiring enzymes by the cofactor tetrahydrobiopterin. Mol Neurobiol. 1999; 19(1):79-96. [PubMed: 10321973]

48. Olsson CA, Anney RJ, Lotfi-Miri M, Byrnes GB, Williamson R, Patton GC. Association between the COMT Val158Met polymorphism and propensity to anxiety in an Australian population-based longitudinal study of adolescent health. Psychiatr Genet. 2005; 15(2):109-115. [PubMed: 15900225]

49. Price DD, Hu JW, Dubner R, Gracely RH. Peripheral suppression of first pain and central summation of second pain evoked by noxious heat pulses. Pain. 1977; 3(1):57-68. [PubMed: 876667]

50. Purcell S, Neale B, Todd-Brown K, Thomas L, Ferreira M, Bender D, Maller J, Sklar P, de Bakker P, Daly M, Sham P. PLINK: a tool set for whole-genome association and population-based linkage analyses. Am J Hum Genet. 2007; 81(3):559-575. [PubMed: 17701901]

51. Raja SN. Role of the sympathetic nervous system in acute pain and inflammation. Ann Med. 1995; 27(2):241-246. [PubMed: 7632421] 
52. Ramachandran R, Ploug KB, Hay-Schmidt A, Olesen J, Jansen-Olesen I, Gupta S. Nitric oxide synthase (NOS) in the trigeminal vascular system and other brain structures related to pain in rats. Neurosci Lett. 2010; 484(3):192-196. [PubMed: 20736047]

53. Scanlon PD, Raymond FA, Weinshilboum RM. Catechol-O-methyltransferase: thermolabile enzyme in erythrocytes of subjects homozygous for allele for low activity. Science. 1979; 203(4375):63-65. [PubMed: 758679]

54. Schmidtko A, Tegeder I, Geisslinger G. No NO, no pain? The role of nitric oxide and cGMP in spinal pain processing. Trends Neurosci. 2009; 32(6):339-346. [PubMed: 19414201]

55. Schultz E, Nissinen E, Kaakkola S. Determination of catechol-O-methyltransferase activity in erythrocytes by high performance liquid chromatography with electrochemical detection. Biomed Chromatogr. 1989; 3(2):64-67. [PubMed: 2736320]

56. Shield AJ, Thomae BA, Eckloff BW, Wieben ED, Weinshilboum RM. Human catechol Omethyltransferase genetic variation: gene resequencing and functional characterization of variant allozymes. Mol Psychiatry. 2004; 9(2):151-160. [PubMed: 14966473]

57. Slade GD, Conrad MS, Diatchenko L, Rashid NU, Zhong S, Smith S, Rhodes J, Medvedev A, Makarov S, Maixner W, Nackley AG. Cytokine biomarkers and chronic pain: association of genes, transcription, and circulating proteins with temporomandibular disorders and widespread palpation tenderness. Pain. 2011; 152(12):2802-2812. [PubMed: 22000099]

58. Slade GD, Diatchenko L, Ohrbach R, Maixner W. Orthodontic Treatment, Genetic Factors and Risk of Temporomandibular Disorder. Semin Orthod. 2008; 14(2):146-156. [PubMed: 18663384]

59. Sladek-Chelgren S, Weinshilboum RM. Catechol-o-methyltransferase biochemical genetics: human lymphocyte enzyme. Biochem Genet. 1981; 19(11-12):1037-1053. [PubMed: 7337686]

60. Tchivileva IE, Lim PF, Smith SB, Slade GD, Diatchenko L, McLean SA, Maixner W. Effect of catechol-O-methyltransferase polymorphism on response to propranolol therapy in chronic musculoskeletal pain: a randomized, double-blind, placebo-controlled, crossover pilot study. Pharmacogenet Genomics. 2010; 20(4):239-248. [PubMed: 20216107]

61. Tegeder I, Costigan M, Griffin RS, Abele A, Belfer I, Schmidt H, Ehnert C, Nejim J, Marian C, Scholz J, Wu T, Allchorne A, Diatchenko L, Binshtok AM, Goldman D, Adolph J, Sama S, Atlas SJ, Carlezon WA, Parsegian A, Lotsch J, Fillingim RB, Maixner W, Geisslinger G, Max MB, Woolf CJ. GTP cyclohydrolase and tetrahydrobiopterin regulate pain sensitivity and persistence. Nat Med. 2006; 12(11):1269-1277. [PubMed: 17057711]

62. Tenhunen J, Salminen M, Jalanko A, Ukkonen S, Ulmanen I. Structure of the rat catechol-Omethyltransferase gene: separate promoters are used to produce mRNAs for soluble and membrane-bound forms of the enzyme. DNA Cell Biol. 1993; 12(3):253-263. [PubMed: 8466648]

63. Tsao D, Shabalina SA, Gauthier J, Dokholyan NV, Diatchenko L. Disruptive mRNA folding increases translational efficiency of catechol-O-methyltransferase variant. Nucleic Acids Res. 2011; 39(14):6201-6212. [PubMed: 21486747]

64. Tuomainen P, Reenila I, Mannisto PT. Validation of assay of catechol-O-methyltransferase activity in human erythrocytes. J Pharm Biomed Anal. 1996; 14(5):515-523. [PubMed: 8738181]

65. van Meurs JB, Uitterlinden AG, Stolk L, Kerkhof HJ, Hofman A, Pols HA, Bierma-Zeinstra SM. A functional polymorphism in the catechol-O-methyltransferase gene is associated with osteoarthritis-related pain. Arthritis Rheum. 2009; 60(2):628-629. [PubMed: 19180497]

66. Vargas-Alarcon G, Fragoso JM, Cruz-Robles D, Vargas A, Vargas A, Lao-Villadoniga JI, GarciaFructuoso F, Ramos-Kuri M, Hernandez F, Springall R, Bojalil R, Vallejo M, Martinez-Lavin M. Catechol-O-methyltransferase gene haplotypes in Mexican and Spanish patients with fibromyalgia. Arthritis Res Ther. 2007; 9(5):R110. [PubMed: 17961261]

67. Voelker P, Sheese BE, Rothbart MK, Posner MI. Variations in catechol-O-methyltransferase gene interact with parenting to influence attention in early development. Neuroscience. 2009; 164(1): 121-130. [PubMed: 19482061]

68. Ware, J.; Kosinski, M.; Keller, S. SF-12 : how to score the SF-12 physical and mental health summary scales. Boston: Massachusetts The Health Institute, New England Medical Center; 1995.

69. Weinshilboum RM. Human biochemical genetics of plasma dopamine-beta-hydroxylase and erythrocyte catechol-o-methyltransferase. Hum Genet Suppl. 1978; (1):101-112. [PubMed: 285022] 
70. Wise PM, Dubal DB, Wilson ME, Rau SW, Liu Y. Estrogens: trophic and protective factors in the adult brain. Front Neuroendocrinol. 2001; 22(1):33-66. [PubMed: 11141318]

71. Wolfe F, Smythe HA, Yunus MB, Bennett RM, Bombardier C, Goldenberg DL, Tugwell P, Campbell SM, Abeles M, Clark P, et al. The American College of Rheumatology 1990 Criteria for the Classification of Fibromyalgia. Report of the Multicenter Criteria Committee. Arthritis Rheum. 1990; 33(2):160-172. [PubMed: 2306288]

72. Zubieta JK, Heitzeg MM, Smith YR, Bueller JA, Xu K, Xu Y, Koeppe RA, Stohler CS, Goldman D. COMT val158met genotype affects mu-opioid neurotransmitter responses to a pain stressor. Science. 2003; 299(5610):1240-1243. [PubMed: 12595695] 
A COMT activity

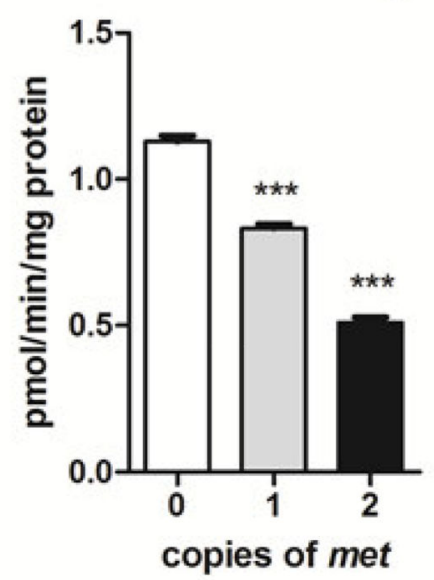

C COMT activity
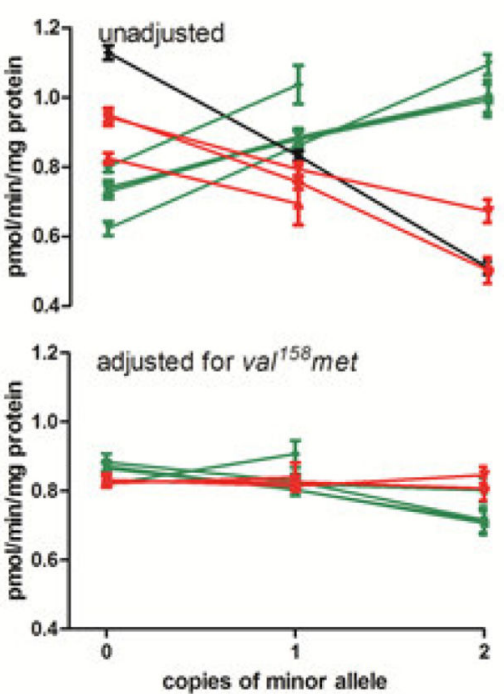

- rs2020917(C>T) - rs.165774(G>A)

\# rs737865 (A>G) \# rs9332381 (C>G)

- $r \$ 165599(A>G)+r \$ 4680(A>G)$

$\rightarrow r s 6269(A>G) \rightarrow r s 1544325(G>A)$

$\rightarrow \mathrm{rs} 174697(\mathrm{G}>\mathrm{A})$
B

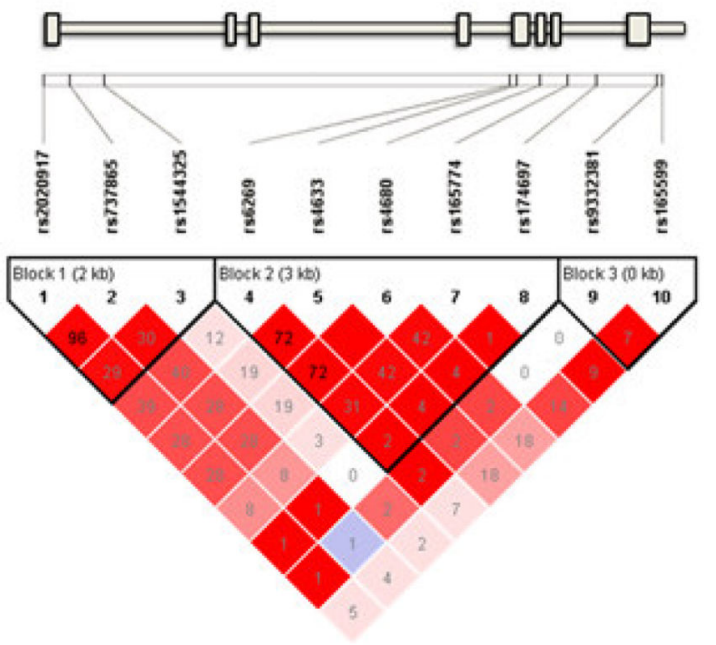

D COMT activity

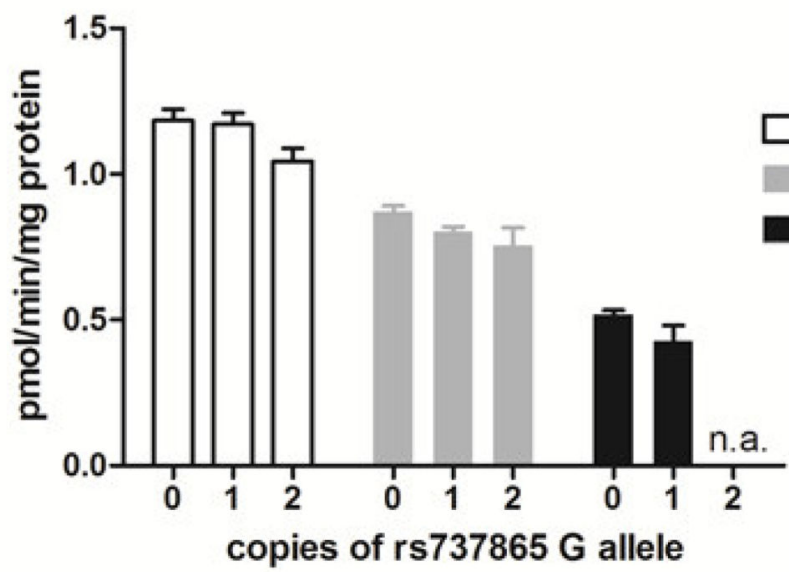

Fig. 1. COMT genotype effects COMT activity

A. COMT val ${ }^{158}$ met genotype effects COMT activity, such that individuals with 1 or 2 copies of the met allele exhibit reduced activity. Data represent mean \pm s.e.m. $* * * p<$

0.0001. B. Linkage disequilibrium plot of the genotyped SNPs in the COMT gene locus. The gene diagram indicates the location of each SNP with respect to exons (boxes) and introns of the gene. The color of each box in the LD plot depicts the strength of LD between aligned SNPs according to D' (darker red indicates stronger LD), and the number in the box is the corresponding $\mathrm{r}^{2}$ value. C. COMT activity levels of each genotype are shown for all COMT 
SNPs tested. Symbols and lines are colored green if the respective minor allele is associated with increased COMT activity, and red with decreased COMT activity; the rs4680 $\mathrm{val}^{158}$ met is shown in black. In the top panel genotype effects of each SNP are unadjusted; in the bottom panel each SNP effect is adjusted for val ${ }^{158}$ met genotype. D. COMT activity level of each genotype of rs737865, stratified by val ${ }^{158}$ met genotype, shows that the minor $\mathrm{G}$ allele of this SNP is associated with decreased COMT activity after the confounding effect of val $^{158}$ met is removed. 

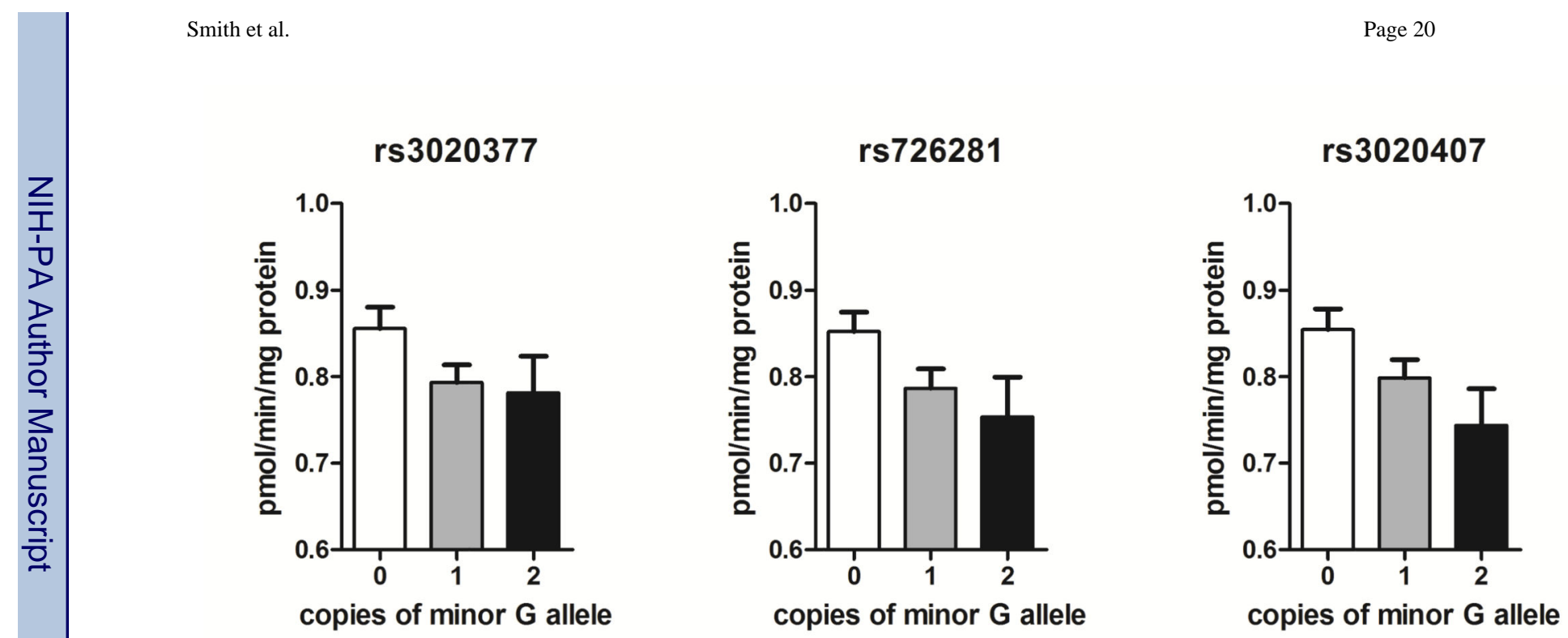

Fig. 2. ESR1 SNP effects on COMT activity

All three ESRI SNPs showed significant $(\mathrm{p}<0.05)$ association with COMT activity using a codominant model, although the dominant model provides a better fit for the data for rs3020377. Data represent mean \pm s.e.m. 
A

COMT activity

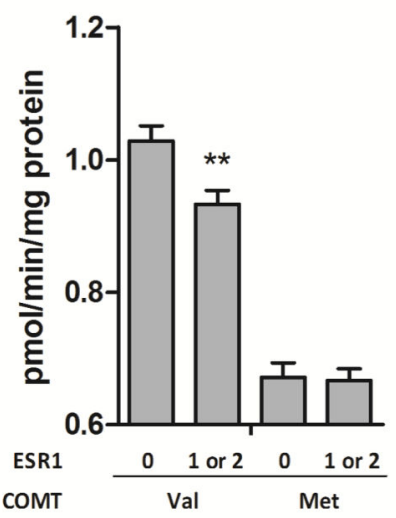

D

pain unpleasantness

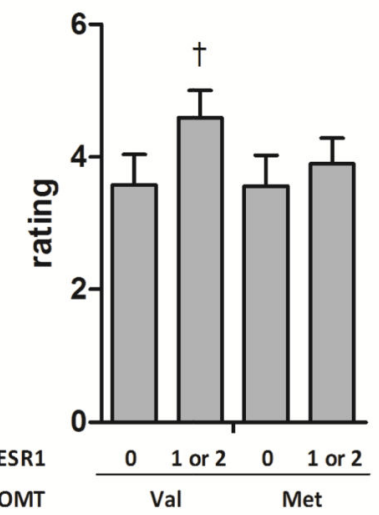

B

physical functioning

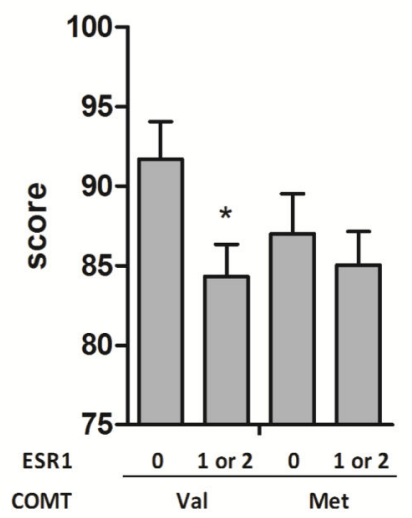

$\mathbf{E}$

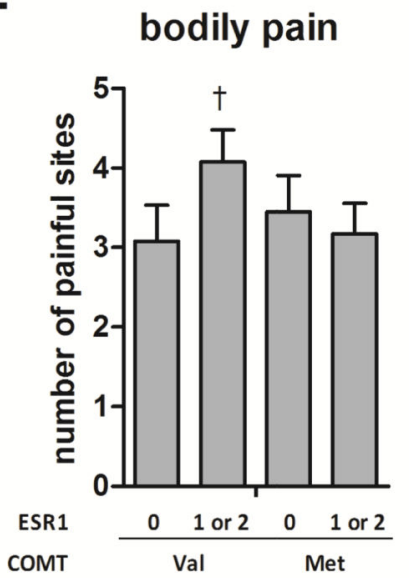

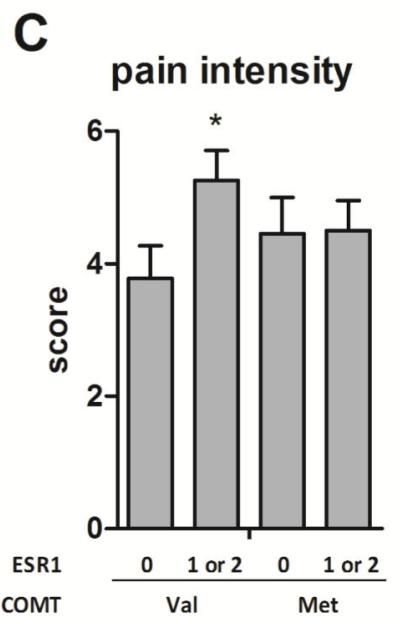

Fig. 3. COMT $\times$ ESR1 effects on COMT activity and pain phenotypes

For genotypes of the ESRI SNP rs3020377, all carriers of the minor G allele were combined (dominant test) and stratified by carriers of COMT alleles val and met. Significance level shown is that of the test of the $\mathrm{G}$ allele carriers against the reference of the major allele homozygote group, within val carriers only. Among val carriers, the ESR1 rs3020377 SNP produced effects on A. COMT enzymatic activity, B. physical functioning subscale of the SF12 questionnaire, C. pain intensity rating using the Gracely scale of the SPSR, D. pain unpleasantness rating using the Gracely Pain Scale of the SPSR, and $\mathbf{E}$. count of the number of bodily sites painful upon palpation by clinical examiner. For each phenotype, rs3020377 modulates the effect of the $v a l$ allele, but not the met allele, of COMT. The G allele of rs3020377 decreased COMT activity and physical functioning, and increased nociceptive phenotypes of pain intensity, unpleasantness, and distribution across body sites. Data are quantitative trait means \pm s.e.m. $\dagger \mathrm{p}<0.1 * \mathrm{p}<0.05 * * \mathrm{p}<0.01$ 
A

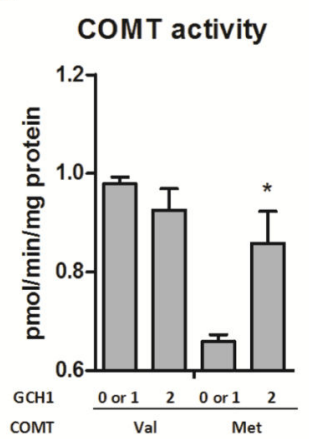

E

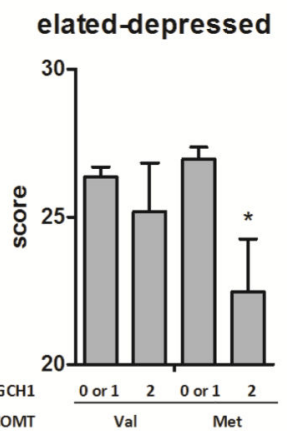

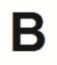

algometer threshold temporalis

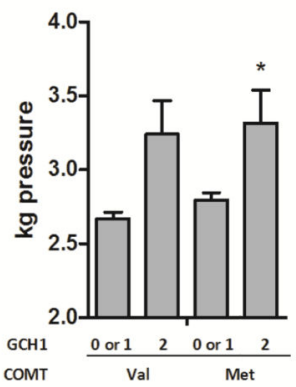

F

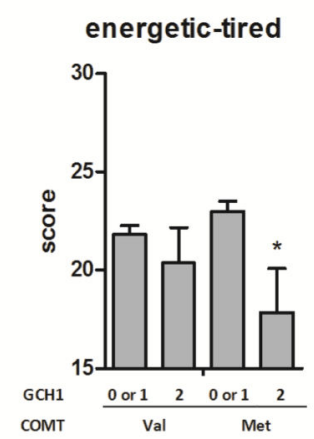

C

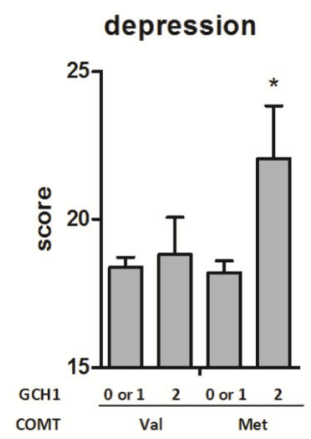

G

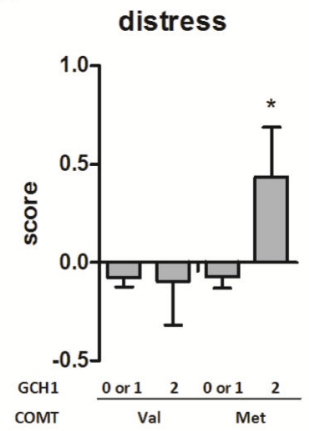

D

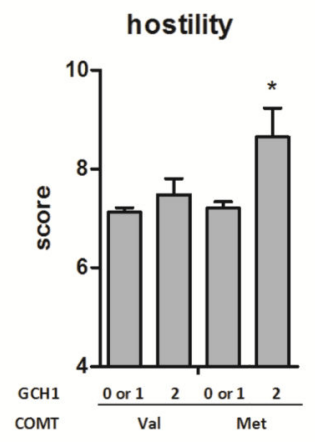

H

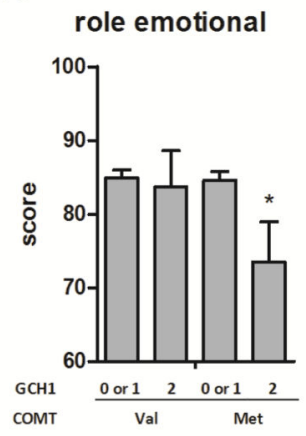

Fig. 4. COMT $\times$ GCH1 effects on COMT activity and pain phenotypes

The GCHI SNP rs 10483639 showed a recessive mode of inheritance, and was stratified by carriers of the COMT alleles val and met. Significance level shown is that of the test of the C allele homozygotes against the reference of the major allele carriers, within met carriers only. Among met carriers, the GCH1 rs10483639 SNP produced effects on A. COMT enzymatic activity, B. algometer pressure at which pain is detected, measured at the temporalis muscle, C. depression subscale of the SCL90 questionnaire, D. hostility subscale of the SCL90, E. elated-depressed axis of the POMS, F. energetic-tired axis of the POMS. G. distress subscale of the PSS, and $\mathbf{H}$. dysfunction in daily activities due to emotional factors, measured by the SF12 questionnaire. Carrying two copies of the rs $10483639 \mathrm{C}$ allele raised COMT activity in met carriers to the level of val carriers, but had no effect in the high-activity val carriers. The $\mathrm{C}$ allele was associated with higher algometer threshold in both val and met carriers, but was associated with more negative psychological characteristics in met carriers only. Data are quantitative trait means \pm s.e.m. $* \mathrm{p}<0.05$. 


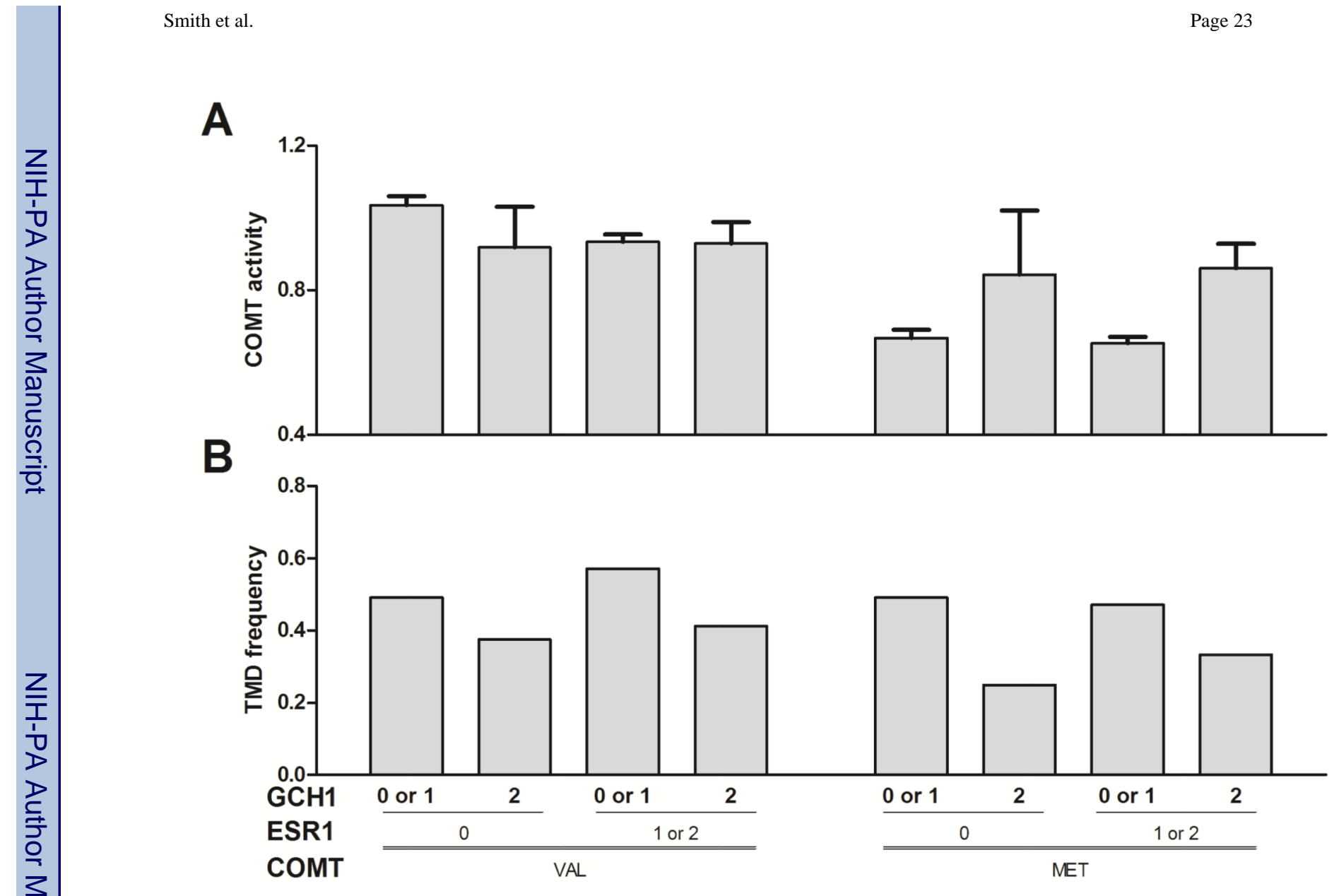

Fig. 5. Three-way interaction between COMT, ESR1, and GCH1 SNPs on COMT activity and TMD risk

A. COMT enzyme activity (means \pm s.e.m.) and B. TMD frequency is plotted for each genotype. The $\mathrm{GCH} 1$ rs $10483639 \mathrm{C}$ allele increases COMT activity and reduces TMD risk among met carriers, while the ESR1 rs $3020377 \mathrm{G}$ allele decreases COMT activity and increases TMD risk among val carriers with only 0 or 1 copy of the GCH1 rs10483639 C allele. 


\section{Table 1}

COMT pathway SNP effects on S-COMT enzymatic activity

\begin{tabular}{lrrrr}
\hline & Val & \multicolumn{2}{c}{ Met } \\
\hline & Beta (S.E.M.) & P & Beta (S.E.M.) & P \\
\hline rs2066470 $($ MTHFR $)$ & $-0.020(0.03)$ & 0.56 & $0.080(0.03)$ & 0.010 \\
\hline rs3020377 dom $($ ESRI $)$ & $0.048(0.02)$ & 0.0021 & $0.002(0.01)$ & 0.87 \\
\hline rs10483639 rec $(\boldsymbol{G C H I})$ & $0.026(0.03)$ & 0.39 & $-0.10(0.03)$ & 0.0030 \\
\hline
\end{tabular}

Selected SNPs showed differential effects on S-COMT activity, based on $v a l{ }^{158_{\text {met }}}$ carrier status. The MTHFR (rs2066470) and GCHI (rs10483639) SNPs were associated with S-COMT activity only in the low activity met carriers; the ESR1 (rs3020377) SNP was associated only in the high activity val carriers. Data represent the beta coefficient and s.e.m. of the SNP genotype term of a univariate regression model of S-COMT activity. 